\title{
Prevalence of and risk factors for gestational diabetes mellitus in South Africa
}

\author{
S Dias, ${ }^{1,2}$ MSc (Molecular Biology); S Adam, ${ }^{2}$ MB ChB, FCOG (SA), MMed (O\&G), PhD, Cert Maternal and Fetal Medicine (SA); \\ P Rheeder, ${ }^{3} \mathrm{MB}$ ChB, MMed (Int Med), FCP (SA), MSc (Clin Epidemiology), PhD; C Pheiffer, ${ }^{1,4}$ PhD (Medical Biochemistry) \\ ${ }^{1}$ Biomedical Research and Innovation Platform (BRIP), South African Medical Research Council, Cape Town, South Africa \\ ${ }^{2}$ Department of Obstetrics and Gynaecology, Faculty of Health Sciences, University of Pretoria, South Africa \\ ${ }^{3}$ Department of Internal Medicine, Faculty of Health Sciences, University of Pretoria, South Africa \\ ${ }^{4}$ Division of Medical Physiology, Department of Biomedical Sciences, Faculty of Medicine and Health Sciences, Stellenbosch University, \\ Cape Town, South Africa
}

Corresponding author: C Pheiffer (carmen.pheiffer@mrc.ac.za)

Gestational diabetes mellitus (GDM) is associated with adverse maternal, fetal and perinatal complications. Without appropriate glucose management, women with GDM and their offspring have an increased risk of developing type 2 diabetes and other metabolic conditions later in life, thereby adding to the growing burden of non-communicable diseases (NCDs). This review provides an update of GDM in South Africa (SA), showing that its prevalence is increasing, and highlights treatment and management strategies currently employed. Although the increase in GDM prevalence may partly be due to less stringent diagnostic criteria, the role of the increasing obesogenic environment in SA is an additional factor. Future research should focus on reducing the rising obesity epidemic and in so doing aim to prevent the development of GDM in SA. Such initiatives will have a positive impact on decreasing maternal and child morbidity and mortality and the future burden of NCDs.

S Afr Med J 2019;109(7):463-467. DOI:10.7196/SAMJ.2019.v109i7.14127

Gestational diabetes mellitus (GDM), defined as glucose intolerance with onset or first recognition during pregnancy, ${ }^{[1]}$ is one of the leading causes of morbidity and mortality for mothers and infants worldwide. Globally, $16.2 \%$ (21.3 million) of live births are associated with hyperglycaemia in pregnancy, of which $86.4 \%$ are due to GDM, $6.2 \%$ to pre-existing type 1 diabetes (T1D) or type 2 diabetes (T2D), and $7.4 \%$ to $\mathrm{T} 1 \mathrm{D}$ and $\mathrm{T} 2 \mathrm{D}$ first detected during pregnancy. ${ }^{[2]}$ The prevalence of GDM is rapidly increasing worldwide, possibly owing to advanced child-bearing age and obesity. This is particularly concerning, as South African (SA) women are considered among the most overweight globally. ${ }^{\left[{ }^{[3]}\right.} \mathrm{GDM}$ is associated with maternal (pre-eclampsia, increase in caesarean deliveries, birth trauma), fetal (macrosomia, hypoglycaemia, shoulder dystocia) and perinatal (respiratory distress syndrome, jaundice, metabolic derangements) complications, while mothers and their offspring are at risk of developing obesity, T2D and other metabolic conditions later in life. GDM thus poses a threat to maternal and child well-being, while its impact on the burden of non-communicable diseases (NCDs) is undeniable. This review provides an update of GDM in SA, focusing on risk factors and prevalence. Furthermore, we highlight recommendations for future research.

\section{Risk factors for gestational diabetes mellitus}

The exact mechanism underlying GDM is not yet fully elucidated, although it is speculated that women who develop GDM may have underlying insulin resistance and genetic susceptibility. ${ }^{[4]}$ GDM is reported to affect $\sim 14 \%$ of pregnancies globally; however, rates between $1 \%$ and $28 \%$ are reported in different regions and vary according to ethnicity, ${ }^{[5]}$ geographical location (urban v. rural), ${ }^{[6]}$ environmental factors and screening and diagnostic strategies employed. ${ }^{[7]}$ In the USA, for example, the prevalence of GDM was reported to be $11.1 \%$ in Asian Indians and $4.1 \%$ in non-Hispanic whites, ${ }^{[5]}$ while in Tanzania, the prevalence of GDM was $1 \%$ and $8.4 \%$ in a rural and urban setting, respectively. ${ }^{[6]}$ Although data are scant, the prevalence of GDM in SA is estimated to be $1.6-25.8 \%$, based on various screening and diagnostic strategies employed. ${ }^{[8,9]}$

Other definable risk factors that affect GDM prevalence include advanced maternal age, overweight and obesity, family history of diabetes, previous history of GDM and previous adverse pregnancy outcomes (Table 1). ${ }^{[10]}$ Alarmingly, the rate of obesity is increasing dramatically, with SA now regarded as one of the world's most obese nations. ${ }^{[1]}$ According to recent statistics, $~ 69 \%$ of SA women are overweight or obese. ${ }^{[3]}$ The increasing risk of obesity is largely due to changes in lifestyle, which have contributed to the increasing prevalence of T2D and metabolic syndrome, particularly among females. ${ }^{[11]}$ Although universal screening, whereby all pregnant women undergo the diagnostic $75 \mathrm{~g}$ oral glucose tolerance test (OGTT) at $24-28$ weeks of gestation, has been widely advocated as

\section{Table 1. Risk factors for gestational diabetes mellitus}

Advanced maternal age ( $\geq 35$ years)
Overweight and obesity (BMI $\geq 25 \mathrm{~kg} / \mathrm{m}^{2}$ or $\left.\geq 30 \mathrm{~kg} / \mathrm{m}^{2}\right)^{*}$
Family history of diabetes mellitus
Previous history of gestational diabetes mellitus
High-risk ethnic groups (Hispanic, African, native American,
Asian, Pacific islander, indigenous Australian)
Previous adverse pregnancy outcomes (e.g. recurrent miscarriages,
congenital abnormalities, stillbirths, macrosomia)
BMI = body mass index.


the recommended screening strategy for GDM, ${ }^{[12]}$ selective screening based on risk factors is now predominantly used in SA, as it is considered less costly than subjecting all women to laboratory testing. However, risk factor-based selective screening has been found to have poor sensitivity and specificity in many studies, ${ }^{[13,14]}$ including our study, ${ }^{[9]}$ and performs poorly as a screening tool for GDM. Moreover, selective screening places a high demand on healthcare workers to identify patients who should be screened and is often poorly adhered to, leading to inadequate screening and testing of GDM.

\section{HIV and gestational diabetes mellitus}

SA has the highest burden of HIV globally, with 7.1 million people living with the virus, ${ }^{[15]}$ and $\sim 19 \%$ of adults (15 - 49 years of age) affected by the disease ${ }^{[16]} \mathrm{HIV}$ infection and antiretroviral therapy dysregulate glucose metabolism and are associated with an increased risk of glucose intolerance and metabolic disease. ${ }^{[17-19]}$ There is evidence that antiretroviral therapy, particularly first-generation protease inhibitors, induces insulin resistance in both pregnant and non-pregnant women. ${ }^{[20]}$ The risk of developing GDM is shown to be more common in HIV-infected women receiving combined antiretroviral therapy, especially with protease inhibitors. ${ }^{[1,22]}$ Although protease inhibitors have been replaced by non-nucleoside reverse transcriptase inhibitors, which are considered safer, they too affect glucose homeostasis, ${ }^{[23]}$ thus requiring further investigation. Current data in SA show no association between HIV infection and antiretroviral therapy and GDM. ${ }^{[9]}$

\section{Complications of gestational diabetes mellitus}

GDM is associated with adverse short- and long-term pregnancy outcomes in mothers and their offspring (Table 2). A study of 57629 women with GDM reported that the prevalence of caesarean delivery, macrosomia, preterm birth and pre-eclampsia was $27.8 \%$, $15.7 \%, 8.4 \%$ and $2.6 \%$, respectively. ${ }^{[24]}$ Fetal macrosomia is a common adverse obstetric outcome, affecting $\sim 15-45 \%$ of neonates born to women with GDM, and is associated with an increased risk of caesarean delivery, shoulder dystocia, birth injury, respiratory distress syndrome and neonatal hypoglycaemia. ${ }^{[25,26]}$ Furthermore, $\sim 50 \%$ of women with GDM will develop T2D within 10 years, ${ }^{[27]}$ while evidence increasingly shows that women with GDM have a 56\% higher risk of developing cardiovascular disease ${ }^{[28]}$ and an increasing risk of metabolic syndrome later in life. ${ }^{[29]}$ GDM is associated with an abnormal intrauterine environment that negatively affects the long-term health of offspring, possibly through epigenetic changes. It is estimated that children born to mothers with GDM have an 8 -fold increased risk of developing T2D and prediabetes compared with children born to mothers with normoglycaemic pregnancies. ${ }^{[30]}$ Treatment of GDM improves outcome; therefore, early detection and appropriate management are critical to prevent pregnancy complications. However, a challenge that hampers the early detection and management of GDM is the current lack of global consensus on GDM screening and diagnosis, which varies between countries and institutions. A recent study conducted by Meek et al. ${ }^{[31]}$ found that women who were diagnosed with GDM according to the stringent International Association of Diabetes in Pregnancy Study Groups (IADPSG) criteria, but were missed when using the National Institute for Health and Care Excellence (NICE) criteria, had a substantial risk of obstetric complications, such as macrosomia, caesarean section and polyhydramnios.

\section{Prevalence of gestational diabetes mellitus in South Africa}

SA is undergoing an epidemiological transition characterised by an increase in NCDs due to urbanisation, nutritional transition towards a diet consisting of high fat and refined sugars and sociocultural factors involving perception of overweight as a measure of success and beauty. Approximately $69 \%$ of SA women are overweight, $40 \%$ are obese and $20 \%$ are morbidly obese, ${ }^{[3,32]}$ and are considered among the most overweight women globally, particularly those of reproductive age. Accordingly, GDM has rapidly increased in SA, with the prevalence ranging from $1.6 \%$ to $25.8 \%$ between 1969 and 2018 (Table 3). The first GDM prevalence study was conducted in 1969 among Indian women from KwaZulu-Natal Province using the $100 \mathrm{~g}$ OGTT. A prevalence of $23.8 \%$ and $8.3 \%$ was reported in women with and without risk factors, respectively. ${ }^{[33]}$ In 1979, using risk-factor screening and the $50 \mathrm{~g}$ OGTT, a GDM prevalence of $3 \%$ was reported in women of mixed ethnic ancestry in Western Cape Province. ${ }^{[34]}$ Using the World Health Organization (WHO) 1985 diagnostic criteria, Ranchod et al. ${ }^{[8]}$ in KwaZulu-Natal, reported a GDM prevalence of $1.6 \%$ and $3.8 \%$ in women of Indian and

Table 2. Adverse outcomes associated with gestational diabetes mellitus

\begin{tabular}{|c|c|c|}
\hline & Mother & Offspring \\
\hline \multirow[t]{8}{*}{ Short-term } & Spontaneous miscarriage & Structural malformations (e.g. brain, heart) \\
\hline & Pre-eclampsia/pregnancy-induced hypertension & Macrosomia \\
\hline & Infections (e.g. urinary tract, puerperal sepsis) & Shoulder dystocia - birth trauma \\
\hline & Caesarean delivery & $\begin{array}{l}\text { Premature birth - metabolic complications (hypoglycaemia, } \\
\text { hypocalcaemia) }\end{array}$ \\
\hline & $\begin{array}{l}\text { Labour complications, including instrumental } \\
\text { deliveries and birth trauma }\end{array}$ & Polycythaemia/jaundice \\
\hline & Preterm delivery & Respiratory distress syndrome \\
\hline & Polyhydramnios & Cardiomyopathy/arrhythmias \\
\hline & Postpartum haemorrhage & Stillbirth \\
\hline \multirow[t]{5}{*}{ Long-term } & Weight gain/obesity & Obesity \\
\hline & $\begin{array}{l}\text { Gestational diabetes mellitus in subsequent } \\
\text { pregnancies }\end{array}$ & Type 1 diabetes \\
\hline & Type 2 diabetes & Type 2 diabetes \\
\hline & Cardiovascular disease & Metabolic syndrome \\
\hline & Metabolic syndrome & \\
\hline
\end{tabular}




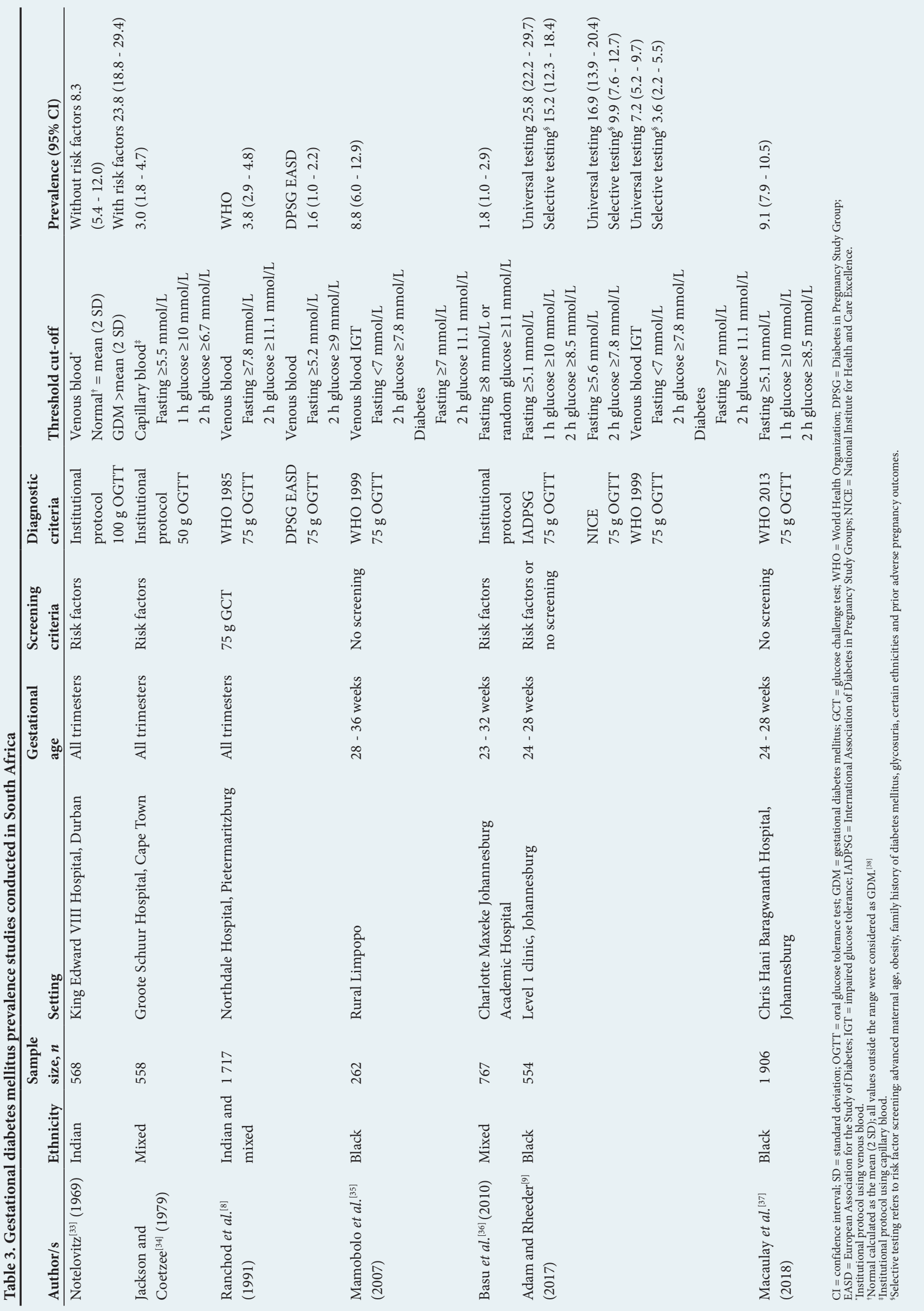


mixed ethnic ancestry, respectively. ${ }^{[8]}$ A population-based study conducted in rural Limpopo Province reported a GDM prevalence of $8.8 \%$ in black women, using the WHO 1999 diagnostic criteria, ${ }^{[35]}$ while a study of overweight and obese pregnant women of mixed ethnic ancestry in Johannesburg, Gauteng Province, showed a GDM prevalence of $1.8 \%$ using random and fasting glucose concentrations. ${ }^{[36]}$ More recently, using the IADPSG criteria, a high prevalence of GDM $(25.8 \%)$ was reported in black women from Johannesburg. ${ }^{[9]}$ To date, the largest GDM prevalence study in SA found a prevalence of $9.1 \%$ in black women from Johannesburg, using the revised WHO 2013 diagnostic criteria, which are similar to the IADPSG criteria. ${ }^{[37]}$

Disparities in the prevalence of GDM were observed between the abovementioned studies, which may be due to the different screening and diagnostic criteria. More recent studies, using the less stringent IADPSG ${ }^{[9]}$ or WHO $2013^{[37]}$ criteria, show an increased prevalence of GDM compared with older criteria, which used higher glucose thresholds. ${ }^{[8,33-36]}$ Thus, although the increased prevalence of GDM may partly be due to diagnostic criteria, the role of the increasing obesogenic environment in SA should not be underestimated. ${ }^{[3]}$ Other factors, such as geographical setting, maternal age and population and environmental differences, could also account for the disparities in prevalence across studies. ${ }^{[9,35,37]}$

\section{Treatment}

Management and treatment of GDM are important to reduce adverse pregnancy outcomes and improve maternal and neonatal health. ${ }^{[39]}$ In SA, pregnant women with GDM are referred to the nearest secondary or tertiary hospital for management and treatment. ${ }^{[40]}$ At the tertiary level, management of GDM is through counselling and health education provided by obstetricians, endocrinologists, dieticians or nurse educators. The primary form of intervention for women with GDM is lifestyle modification, which involves counselling regarding diet and physical activity. A dietary meal plan is provided, which entails reduced sugar and starch intake, increased protein intake and reduced total calorie intake. ${ }^{[40]}$ However, in disadvantaged settings, these lifestyle changes are difficult to adhere to owing to the high cost of healthy food and lack of understanding and social support. A more sustainable approach is to counsel patients on how to reduce the glycaemic index of staple foods. The glycaemic index of carbohydrate-rich foods (e.g. potatoes, pap, pasta, rice) can be reduced by cooking, cooling and reheating, or by adding fats or acids such as lemon juice or vinegar. ${ }^{[41]}$

Pharmacological therapy is initiated for women who fail to reach their glucose targets using diet and exercise. In SA, metformin is the drug of choice to treat GDM, while glyburide is used when metformin and insulin are not available. Although insulin is invasive and used only if metformin fails, it is effective, allows tight glucose control and is considered safe, as it does not cross the placenta. Generally, oral agents are preferred to insulin because of ease of administration, although studies conducted in other settings showed no substantial differences in major outcomes when comparing their benefits and risks. ${ }^{[42,43]}$

\section{Current perspectives and future recommendations}

- The rate of obesity is rising dramatically, thus increasing the prevalence of GDM globally and in SA.

- Untreated GDM negatively affects maternal and child health.

- GDM increases the risk of developing T2D and other NCDs later in life.
- Future research should focus on reducing obesity and preventing the development of GDM.

\section{Conclusions}

The prevalence of GDM is rapidly increasing in SA and is becoming a major public health concern. Without appropriate glucose management, GDM is associated with adverse pregnancy outcomes and an increased risk of future metabolic conditions in mothers and their offspring, further contributing to the growing burden of NCDs. Although the significant increase in the prevalence of GDM observed in recent SA studies may be attributed to the lower diagnostic thresholds used, the role of the increasing obesogenic environment should not be underestimated. Future research should focus on reducing the rising obesity epidemic and in so doing aim to prevent the development of GDM. Such initiatives will have a positive impact on decreasing maternal and child morbidity and mortality and the future burden of NCDs.

Declaration. This publication forms part of SD's PhD degree that will be submitted to the University of Pretoria.

Acknowledgements. None.

Author contributions. All authors contributed to the compilation and writing of this article; $\mathrm{CP}$ and SA conceived the idea for the review; SD wrote the manuscript; and all authors reviewed and edited drafts and approved the final manuscript.

Funding. This work was supported by the National Research Foundation of South Africa for the Thuthuka grant (unique grant no. 99391), and by baseline funding from the South African Medical Research Council (SAMRC).

Conflicts of interest. None.

1. Hod M, Kapur A, Sacks DA, et al. The International Federation of Gynecology and Obstetrics (FIGO) initiative on gestational diabetes mellitus: A pragmatic guide for diagnosis, management, and care. Int J Gynaecol Obstet 2015;131(Suppl 3):S173-S211. https://doi.org/10.1016/s0020-7292(15)30033-3 International Diabetes Federation. IDF diabetes atlas - across the globe. 2017. http://diabetesatlas.org/ across-the-globe.html (accessed 20 May 2019).

3. Statistics South Africa. South Africa demographic and health survey, 2016. Key indicators report. 2017. https://www.statssa.gov.za/publications/Report/2003-00-09/Report/2003-00-092016.pdf (accessed 5 January 2019).

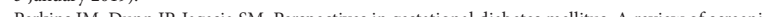

Perkins JM, Dunn JP, Jagasia SM. Perspectives in gestational diabetes mellitus: A review of screening
diagnosis, and treatment. Clin Diab 2007;25(2):57-62. https://doi.org/10.2337/diaclin.25.2.57 Hedderson MM, Darbinian JA, Ferrara A. Disparities in the risk of gestational diabetes by raceethnicity and country of birth. Paediatr Perinat Epidemiol 2010;24(5):441-448. https://doi.org/ 10.1111/j.1365-3016.2010.01140.x

6. Mwanri AW, Kinabo J, Ramaiya K, Feskens EJM. Prevalence of gestational diabetes mellitus in urban and rural Tanzania. Diabet Res Clin Pract 2014;103(1):71-78. https://doi.org/10.1016/j. diabres.2013.11.021

7. Pastakia SD, Njuguna B, Onyango BA, et al. Prevalence of gestational diabetes mellitus based on various screening strategies in western Kenya: A prospective comparison of point of care diagnostic methods. BMC Pregn Child 2017;17:226. https://doi.org/10.1186/s12884-017-1415-4

8. Ranchod HA, Vaughan JE, Jarvis P. Incidence of gestational diabetes at Northdale Hospital, Pietermaritzburg. S Afr Med J 1991;80(1):14-16.

9. Adam S, Rheeder P. Screening for gestational diabetes mellitus in a South African population: Prevalence, comparison of diagnostic criteria and the role of risk factors. S Afr Med J 2017;107(6):523-527. Prevalence, comparison of diagnostic criteria and

10. Pons RS, Rockett FC, Rubin B de A, Oppermann MLR, Bosa VL. Risk factors for gestational diabetes mellitus in a sample of pregnant women diagnosed with the disease. Diabetol Metab Syndr 2015;7(Suppl 1):A80. https://doi.org/10.1186/1758-5996-7-s1-a80

11. Sartorius B, Veerman LJ, Manyema M, Chola L, Hofman K. Determinants of obesity and associated population attributability, South Africa: Empirical evidence from a national panel survey, 2008 - 2012. PLOS ONE 2015;10(6). https://doi.org/10.1371/journal.pone.0130218

12. International Association of Diabetes and Pregnancy Study Groups Consensus Panel. IADPSG recommendations on the diagnosis and classification of hyperglycemia in pregnancy. Diabet Care 2010;33(3):676-682.

13. O'Sullivan JB, Mahan CM, Charles D, Dandrow RV. Screening criteria for high-risk gestational diabetic patients. Am J Obstet Gynecol 1973;116(7):895-900.

14. Cosson E, Cussac-Pillegand C, Benbara A, et al. The diagnostic and prognostic performance of a selective screening strategy for gestational diabetes mellitus according to ethnicity in Europe. J Clin Endocrinol Metab 2014;99(3):996-1005. https://doi.org/10.1210/jc.2013-3383

15. Joint United Nations Programme on HIV/AIDS (UNAIDS). UNAIDS data. 2017. http://www.unaids. . Joint United Nations Programme on HIV/AIDS (UNAIDS). UNAI
org/en/regionscountries/countries/southafrica (30 April 2019).

org/en/regionscountries/countries/southafrica (30 April 2019).
16. Shisana O, Rehle T, Simbayi LC, et al. South African National HIV Prevalence, Incidence and Shisana O, Rehle T, Simbayi LC, et al. South African National HIV Prevalence,
Behaviour Survey, 2012. Cape Town: Human Sciences Research Council (HSRC), 2014.

Behaviour Survey, 2012. Cape Town: Human Sciences Research Council (HSRC), 2014.
7. Dave JA, Lambert EV, Badri M, West S, Maartens G, Levitt NS. Effect of nonnucleoside reverse transcriptase inhibitor-based antiretroviral therapy on dysglycemia and insulin sensitivity in South African HIV-infected patients. J Acquir Immune Defic Syndr 2011;57(4):284-289. https://doi. org/10.1097/qai.0b013e318221863f 
18. Dave JA, Levitt NS, Ross IL, Lacerda M, Maartens G, Blom D. Anti-retroviral therapy increases the prevalence of dyslipidemia in South African HIV-infected patients. PLOS ONE 2016;11(3):e0151911. https://doi.org/10.1371/journal.pone.0151911

19. Noubissi EC, Katte J-C, Sobngwi E. Diabetes and HIV. Curr Diab Rep 2018;18(11):125. https://doi, org/10.1007/s11892-018-1076-3

20. Jao J, Wong M, Dyke RBV, et al. Gestational diabetes mellitus in HIV-infected and -uninfected pregnant women in Cameroon. Diabet Care 2013;36(9):e141-e142. https://doi.org/10.2337/dc13-0968 21. Martí C, Peña JM, Bates I, et al. Obstetric and perinatal complications in HIV-infected women. Analysis of a cohort of 167 pregnancies between 1997 and 2003. Acta Obstet Gynecol Scand 2007;86(4):409-415. https://doi.org/10.1080/00016340601148531

22. Soepnel LM, Norris SA, Schrier VJMM, et al. The association between HIV, antiretroviral therapy, and gestational diabetes mellitus. AIDS. 2017;31(1):113-125. https://doi.org/10.1097/ qad.0000000000001277

23. Brown TT, Li X, Cole SR, et al. Cumulative exposure to nucleoside analogue reverse transcriptase inhibitors is associated with insulin resistance markers in the Multicenter AIDS Cohort Study. AIDS inhibitors is associated with insulin resistance markers in the Multicen

24. Billionnet C, Mitanchez D, Weill A, et al. Gestational diabetes and adverse perinatal outcomes from 716152 births in France in 2012. Diabetologia 2017;60(4):636-644. https://doi.org/10.1007/s00125 017-4206-6

25. Ovesen PG, Jensen DM, Damm P, Rasmussen S, Kesmodel US. Maternal and neonatal outcomes in pregnancies complicated by gestational diabetes. A nation-wide study. J Matern Fetal Neonat Med 2015;28(14):1720-1724. https://doi.org/10.3109/14767058.2014.966677

26. Kamana KC, Shakya S, Zhang H. Gestational diabetes mellitus and macrosomia: A literature review. Ann Nutr Metab 2015;66:14-20. https://doi.org/10.1159/000371628

27. Kim C, Newton KM, Knopp RH. Gestational diabetes and the incidence of type 2 diabetes: A systematic review. Diabet Care 2002;25(10):1862-1868. https://doi.org/10.2337/diacare.25.10.1862

28. Kramer CK, Campbell S, Retnakaran R. Gestational diabetes and the risk of cardiovascular disease in women: A systematic review and meta-analysis. Diabetologia 2019;62(6):905-914. https://doi. org $/ 10.1007 / \mathrm{s} 00125-019-4840-2$

29. De Souza LR, Ray JG, Retnakaran R. Gestational diabetes and the metabolic syndrome. www. intechopen.com (accessed 20 May 2019).

30. Clausen TD, Mathiesen ER, Hansen T, et al. High prevalence of type 2 diabetes and pre-diabetes in adult offspring of women with gestational diabetes mellitus or type 1 diabetes: The role of intrauterine hyperglycemia. Diabet Care 2008;31(2):340-346. https://doi.org/10.2337/dc07-1596

31. Meek CL, Lewis HB, Patient C, Murphy HR, Simmons D. Diagnosis of gestational diabetes mellitus: Falling through the net. Diabetologia 2015;58(9):2003-2012. https://doi.org/10.1007/s00125-015-3647-z
32. Ng M, Fleming T, Robinson $\mathrm{M}$, et al. Global, regional and national prevalence of overweight and obesity in children and adults 1980 - 2013: A systematic analysis. Lancet 2014;384(9945):766-781. https://doi.org/10.1016/S0140-6736(14)60460-8

33. Notelovitz M. Carbohydrate tolerance in the pregnant Natal Indian. S Afr Med J 1969;43(10):259-266.

34. Jackson WP, Coetzee EJ. Gycosuria as an indication for glucose tolerance testing during pregnancy. S Afr Med J 1979;56(22):921-923

35. Mamabolo RL, Alberts M, Levitt NS, Delemarre-van de Waal HA, Steyn NP. Prevalence of gestational diabetes mellitus and the effect of weight on measures of insulin secretion and insulin resistance in third-trimester pregnant rural women residing in the Central Region of Limpopo Province, South Africa. Diabet Med 2007;24(3):233-239. https://doi.org/10.1111/j.1464-5491.2006.02073.x

36. Basu JK, Jeketera CM, Basu D. Obesity and its outcomes among pregnant South African women. Int J Gynaecol Obstet 2010;110(2):101-104. https://doi.org/10.1016/j.ijgo.2010.02.020

37. Macaulay S, Ngobeni M, Dunger DB, Norris SA. The prevalence of gestational diabetes mellitus amongst black South African women is a public health concern. Diabet Res Clin Pract 2018;139:278287. https://doi.org/10.1016/i.diabres.2018.03.012

38. Wootton IDP. Microanalysis in Medical Biochemistry. Edinburgh: Churchill Livingstone, 1974

39. HAPO Study Cooperative Research Group, Metzger BE, Lowe LP, et al. Hyperglycemia and adverse pregnancy outcomes. N Engl J Med 2008;358(19):1991-2002. https://doi.org/10.1097/01. adverse pregnancy outco

40. Muhwava LS, Murphy K, Zarowsky C, Levitt N. Policies and clinical practices relating to the management of gestational diabetes mellitus in the public health sector, South Africa - a qualitative
study. BMC Health Serv Res 2018;18(1):349. https://doi.org/10.1186/s12913-018-3175-x

41. Kinnear T, Wolever TMS, Murphy AM, Sullivan JA, Liu Q, Bizimungu B. Effect of preparation metho on the glycaemic index of novel potato clones. Food Funct 2011;2(8):438-444. https://doi.org/10.1039/ clfo10042d

42. Nicholson W, Bolen S, Witkop CT, Neale D, Wilson L, Bass E. Benefits and risks of oral diabetes agents compared with insulin in women with gestational diabetes: A systematic review. Obstet Gynecol 2009;113(1):193-205. https://doi.org/10.1097/aog.0b013e318190a459

43. Rowan JA, Hague WM, Gao W, Battin MR, Moore MP. Metformin versus insulin for the treatment of gestational diabetes. N Engl J Med 2008;359(1):106. https://doi.org/10.1056/nejmx080015

Accepted 3 May 2019. 